\title{
Determination and Estimation of Allicin in Allium sativum
}

\author{
Sirjan Singh ${ }^{1}$, Asha Jha², Sourya Acharya ${ }^{3}$, Samarth Shukla ${ }^{4}$, Neema Acharya ${ }^{5}$ \\ ${ }^{1,2}$ Department of Pharmacology, Jawaharlal Nehru Medical College, Datta Meghe Institute of Medical \\ Sciences (Deemed to Be University), Sawangi (Meghe), Wardha, Maharashtra, India. ${ }^{3}$ Department of \\ Medicine, Jawaharlal Nehru Medical College, Datta Meghe Institute of Medical Sciences (Deemed to Be \\ University), Sawangi (Meghe), Wardha, Maharashtra, India. ${ }^{4}$ Department of Pathology, Jawaharlal Nehru \\ Medical College, Datta Meghe Institute of Medical Sciences (Deemed to Be University), Sawangi (Meghe), \\ Wardha, Maharashtra, India. 5Department of OBGY, Jawaharlal Nehru Medical College, Datta Meghe Institute \\ of Medical Sciences (Deemed to Be University), Sawangi (Meghe), Wardha, Maharashtra, India.
}

\section{ABSTRACT}

\section{BACKGROUND}

Nature has provided us with many medicinal plants that can be utilized in therapeutic industry and as medications. Since ancient times, mankind has used plants to treat common diseases and some of these traditional medicines have been with us ever since. Garlic (Allium sativum) a herbal spice easily available in our kitchen, is useful in cardiovascular diseases, regulating blood pressure, lowering blood sugar, maintaining cholesterol levels and fighting against some cancers and oxidative distress. Analysis of the pharmacological activity of garlic extracts may therefore make possible the design of less expensive therapies to be used in economically under privileged regions. Moreover, Allicin has been shown to possess biological properties such as antitumor and antioxidant effects. Therefore, there is an increased necessity of research on garlic.

\section{METHODS}

Materials used included garlic from local market, cheesecloth, grinder, test tubes and high-performance liquid chromatography. Garlic was collected and garlic extract was prepared using cheesecloth. It was prepared by grinding and then extracting the garlic sample. Introductory phytochemical panelling was performed to recognize the chemical parts. Garlic mainly consists of sulphur components, so two sulphur tests were done, including lead acetate test and sodium nitroprusside test. Allicin was estimated using high performance liquid chromatography.

\section{RESULTS}

Preliminary tests confirmed the presence of sulphur compounds \& HighPerformance Liquid Chromatography results showed retention time of standard garlic solution similar to the extract used that is 3.011 minutes / $\mathrm{mL}$, hence confirming the presence of allicin. Quantitative estimation showed allicin to be 81.37 $\%$ in the extract made.

\section{CONCLUSIONS}

With the help of two biochemical tests and chromatography, we conclude that garlic has sulphur and allicin.

\section{KEY WORDS}

Garlic, Allicin, High Performance Liquid Chromatography, Phytochemicals
Corresponding Author:

Dr. Sirjan Singh,

Room No. F/01, Shivaji Boys Hostel,

DMIMS Campus, Sawangi

(Meghe), Wardha,

Maharashtra - 442001, India.

E-mail: singhsirjan97@gmail.com

DOI: $10.14260 / \mathrm{jemds} / 2020 / 815$

How to Cite This Article:

Singh $S$, Jha A, Acharya $S$, et al. Determination and estimation of allicin in allium sativum. J Evolution Med Dent Sci 2020;9(49):3711-3715, $10.14260 /$ jemds/2020/815

Submission 08-06-2020,

Peer Review 19-10-2020,

Acceptance 26-10-2020,

Published 07-12-2020.

Copyright (c) 2020 Sirjan Singh et al. This is an open access article distributed under Creative Commons Attribution License [Attribution 4.0 International (CC BY 4.0)] 


\section{BACKGROUND}

Nature has provided us with many medicinal plants that can be utilized in therapeutic industry and as medications. Since ancient times, mankind has used plants to treat common diseases and some of these traditional medicines have been with us ever since. Folk medicine, mainly based on plants, enjoys a respectable position today, especially in the developing countries. ${ }^{1}$ Plants have been used for hundreds of years. In addition, chemical diversity of secondary plant metabolites resulting from their evolution may be equal or superior to that found in common drugs. Apart from the health benefits provided by vitamins and minerals, naturally occurring compounds known as phytochemicals are widely known to provide health benefits. Though, there are evidence of their benefits but not enough evidence to recommend the daily allowance of such compounds. ${ }^{2}$ Also, their long-term benefits are not known.

Garlic (Allium sativum) a herbal spice easily available in our kitchen, useful in cardiovascular diseases, regulating blood pressure, lowering blood sugar, maintaining cholesterol levels and fighting against some cancers and oxidative distress. Garlic contains $0.1-0.36 \%$ of mainly volatile oil which is responsible for its pharmacological properties. It also contains many sulphur compounds including allicin, allyl propyl, diallyl trisulphide and others important for its pharmacological activities. Extracts of garlic has shown promising hypoglycaemic activity and antihypertensive effects in experimental diabetic rats. ${ }^{3-5}$ In-vitro experiments suggest its capability as an agent to suppress LDL (Low-Density Lipoprotein) oxidation and increase HDL (High-Density Lipoprotein).

Garlic is known to carry potent anti-cancerous properties. In terms of hypoglycaemic effect, reduction in fasting glucose has shown greater response when metformin was combined with garlic than with metformin alone.

Allicin (allyl 2-propenethiosulfinate or diallyl thiosulfinate) is the principal bioactive compound present in the aqueous extract of garlic or raw garlic homogenate, which has a powerful antibacterial property and a strong smell. Allicin is produced through enzymatic reaction due to injury to plant tissue. Its precursor is alliin. Alliin and other S-alkyl-lcysteine sulfoxides are hydrolysed by alliinase enzyme. It produces dehydroalanine and allyl sulfenic acid which condense spontaneously to form allicin. Allicin has been shown to possess biological properties such as antitumor and antioxidant effects. The wealth of scientific literature is in the favour of the proposal that garlic consumption have significant effects on lowering blood pressure, prevention of atherosclerosis, reduction of serum cholesterol and triglyceride, inhibition of platelet aggregation, and increasing fibrinolytic activity, and all this has been attributed to the presence of allicin. ${ }^{6}$

Allicin is a reactive sulphur containing species with immense oxidizing properties. It is known to cause change in protein structure due to its oxidizing thiol property. Allicin depicts its antimicrobial activity by reacting with cysteine residue in active elongating amino acid chain, which may cause abortion of translation or misfolded proteins with reduced or no function. Allicin has more of bacteriostatic property than bactericidal. It is equally effective against gram positive and gram-negative bacteria, which gives it an edge over penicillin in terms of pharmaceutical utilisation. Allicin is also known to inhibit fungal spores and hyphae growth, giving it prominent antifungal properties. It has shown promising result against fungi and pest in both in-vivo and in-vitro examination making it of great economic value. ${ }^{6}$

Medical point of view, studies has shown that allicin induces Nrf2 / Keap1, which makes allicin eligible to control various cardiovascular and neurodegenerative disorders. Allicin is known to inhibit two enzymes of cholesterolbiosynthesis pathway, having direct impact on thiol-group of coenzyme A. Allicin's antihypertensive properties has been attributed to the fact that on degradation allicin produces $\mathrm{H}_{2} \mathrm{~S}$, a potent gaseous signalling molecule in regard to bloodpressure regulation. Red blood cells have been known to produce hydrogen sulphide when it reacts with sulphur containing substrates. Allicin degrades into organic polysulphides. These polysulphides provide the sulphur needed by the blood to produce hydrogen sulphide. Hydrogen sulphide reacts with KATP channels causing hyperpolarisation of vascular smooth muscle cells. Hyperpolarisation of vessels is responsible for their vasodilation or vascular relaxation that in turn causes antihypertensive effect. It also inhibits Renin Angiotensin Aldosterone System (RAAS) and prostaglandin synthesis. This causes vasodilation. It's due to allicin contributing in inhibition of Angiotensin Converting Enzyme (ACE) activity. This produces a series of effects, one of which is reduction in angiotensin II (ATII), which is a potent vasoconstrictor. Next is depletion of angiotensin II will decrease the production of aldosterone. All these cascades will lead to depletion of sodium and water from distal convoluted renal tubule, hence decreasing plasma volume as whole. Also, the decrease in utilization of bradykinin through angiotensin converting enzyme inhibition by garlic is known to increase production of NO, further providing valuable input in making the vessels to dilate. Allicin holds a great potential against cancer. Its redox shift in cells in well known. It can cause both caspase-dependent and caspase-independent cell death. 6

The present study focuses on determination of sulphur compound Allicin using biochemical tests and its estimation using HPLC (High Performance Liquid Chromatography), in order to determine its use as medicinal phytochemical.

\section{METHODS}

This is an analytical study conducted over 6 months in the Pharmacology Department, JNMC (Jawaharlal Nehru Medical College), Wardha \& Central Research Laboratory, DMIMS, Wardha.

\section{Materials and Chemicals}

Raw garlic cloves, methanol, distilled water, cheese cloth, sodium nitroprusside, lead acetate, $40 \%$ sodium hydroxide.

\section{Instruments}

High Performance Liquid Chromatography (HPLC) (to estimate concentration), grinder (to grind the garlic cloves), weighing machine. 


\section{Collection of Garlic}

The garlic used for the study was purchased from the local market of Sawangi, Dist. Wardha, and Maharashtra, India. 100 $\mathrm{g}$ of raw garlic was used. $83.26 \mathrm{~g}$ of cloves were collected from it.

\section{Preparation of Garlic Extract}

The outer skin of garlic cloves was peeled. Fresh peeled garlic cloves (83.26 g) was grinded in the grinder. The grinded garlic clove was covered with cheese cloth and pressed with hands under hygienic conditions. The pressed garlic was then collected in a beaker and mixed thoroughly. The garlic extract (Figure 1) produced was collected in wide mouth container and then stored in graduated centrifuged tube. Heat transfer was avoided during this extraction. Sample is filtered through $0.45 \mu \mathrm{m}$ glass filter into HPLC vial and capped for injection.

\section{Preliminary Phytochemical Analysis}

Preliminary phytochemical screening was performed to identify the chemical constituents. Garlic mainly contains the sulphur components so two sulphur tests was carried out.

\section{Sulphur Test / Lead Acetate Test}

$2 \mathrm{~mL}$ extract was taken in a test tube and mixed with $3-4$ drops of lead acetate and $2-3$ drops of $40 \%$ Sodium hydroxide was added and mixed till the precipitate dissolved. The test tube was boiled for 2 mins. and cooled. There was appearance of brownish black precipitate. This confirms the presence of sulphur in prepared extract of garlic. (Figure 2)

\section{Sodium Nitroprusside Test}

Allicin liquid forms thiosulfinate compounds. $2 \mathrm{~mL}$ extract was taken in the test tube and 3 - 4 drops of sodium nitroprusside was added to it. The medium was made alkaline by adding 2 3 drops of $40 \%$ sodium hydroxide. There was appearance of deep violet colour indicating the presence of sulphur in given extract. These two tests were carried out 3 times each to eliminate any error. These components are difficult to measure or detect without HPLC. (Figure 3)

\section{Determination and Estimation of Allicin Using High Performance Liquid Chromatography (HPLC)}

\section{Preparation of Extract for High Performance Liquid} Chromatography

The extract prepared was diluted with distilled water. $196 \mathrm{mg}$ of extract was taken and was diluted with $10 \mathrm{~mL}$ of distilled water. The extract was filtered with 0.45 filter pore and then used for HPLC.

\section{Preparation of Standard for High Performance Liquid Chromatography}

Allimax tablets were used as a source of allicin. One tablet consists of $195 \mathrm{mg}$ of powdered allicin. This $195 \mathrm{mg}$ was diluted with $10 \mathrm{~mL}$ of distilled water. The standard was filtered with 0.45 filter pore and then used as standard for high performance liquid chromatography.
Quantitative Analysis (High Performance Liquid Chromatography Conditions)

- Column: C18

- $\quad$ Solvent as mobile phase: Water : Methanol (50:50)

- Run time: 10 minutes

- Flow rate: $1.0 \mathrm{~mL} /$ minute

- Injection Volume: 20 microliter

- Detector: PDA Detector

- Column temperature: $40^{\circ} \mathrm{C}$

\section{Statistical Analysis}

Descriptive statistics were used, and arithmetic mean values were calculated. There was direct comparison between the values obtained through the high-performance liquid chromatography.

\section{RESULTS}

In this study, high performance liquid chromatography result showed that the retention time of standard garlic solution in water is 3.407 minutes / $\mathrm{mL}$ (Table 1). The retention time of standard garlic solution in methanol is 3.064 minutes / mL (Table 2). While that of garlic extract was noted to be 3.011 minutes / $\mathrm{mL}$ (Table 3). The retention time with the difference within the limit ${ }^{7}$ indicates the presence of allicin in the garlic extract. And by arithmetical calculation the concentration of allicin in the garlic extract was found to be $81.37 \%$.

Although the analysis of allicin is difficult due to its instability, and the current study was an attempt to determine the presence of allicin in garlic extract.

\begin{tabular}{|c|cccc|}
\hline Peak\# & Ret. Time & Area & Height & Area \% \\
1 & 1.545 & 533740 & 36138 & 23.310 \\
2 & 2.401 & 1742897 & 65299 & 76.118 \\
3 & 3.407 & 13101 & 2360 & 0.572 \\
& Total & $\mathbf{2 2 8 9 7 3 9}$ & $\mathbf{1 0 3 7 9 6}$ & $\mathbf{1 0 0 . 0 0 0}$ \\
\hline \multicolumn{5}{c}{ Table 1. Peak Table-Standard 1 (Water) } \\
\hline \multicolumn{4}{c}{ PDA Ch1 240 nm 4 nm } \\
\hline
\end{tabular}

\begin{tabular}{|ccccc|}
\hline Peak\# & Ret. Time & Area & Height & Area \% \\
1 & 1.148 & 20930 & 2782 & 17.54 \\
2 & 3.064 & 98401 & 3182 & 82.460 \\
& Total & $\mathbf{1 1 9 3 3 1}$ & $\mathbf{5 9 6 4}$ & $\mathbf{1 0 0 . 0 0 0}$ \\
\hline \multicolumn{5}{|c|}{ Table 2. Peak Table-Standard 2 (MeOH) } \\
\hline \multicolumn{4}{|c|}{ PDA Ch1 240 nm 4 nm }
\end{tabular}

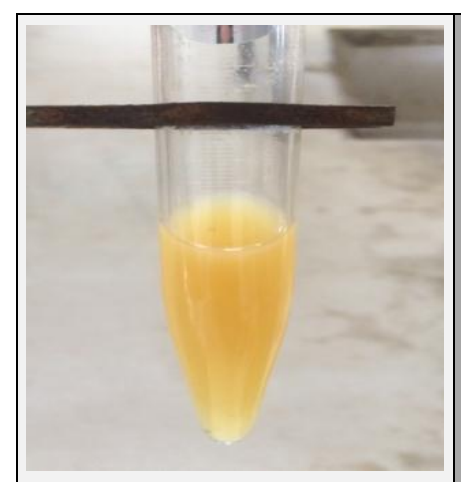

Figure 1.

Garlic Extract 

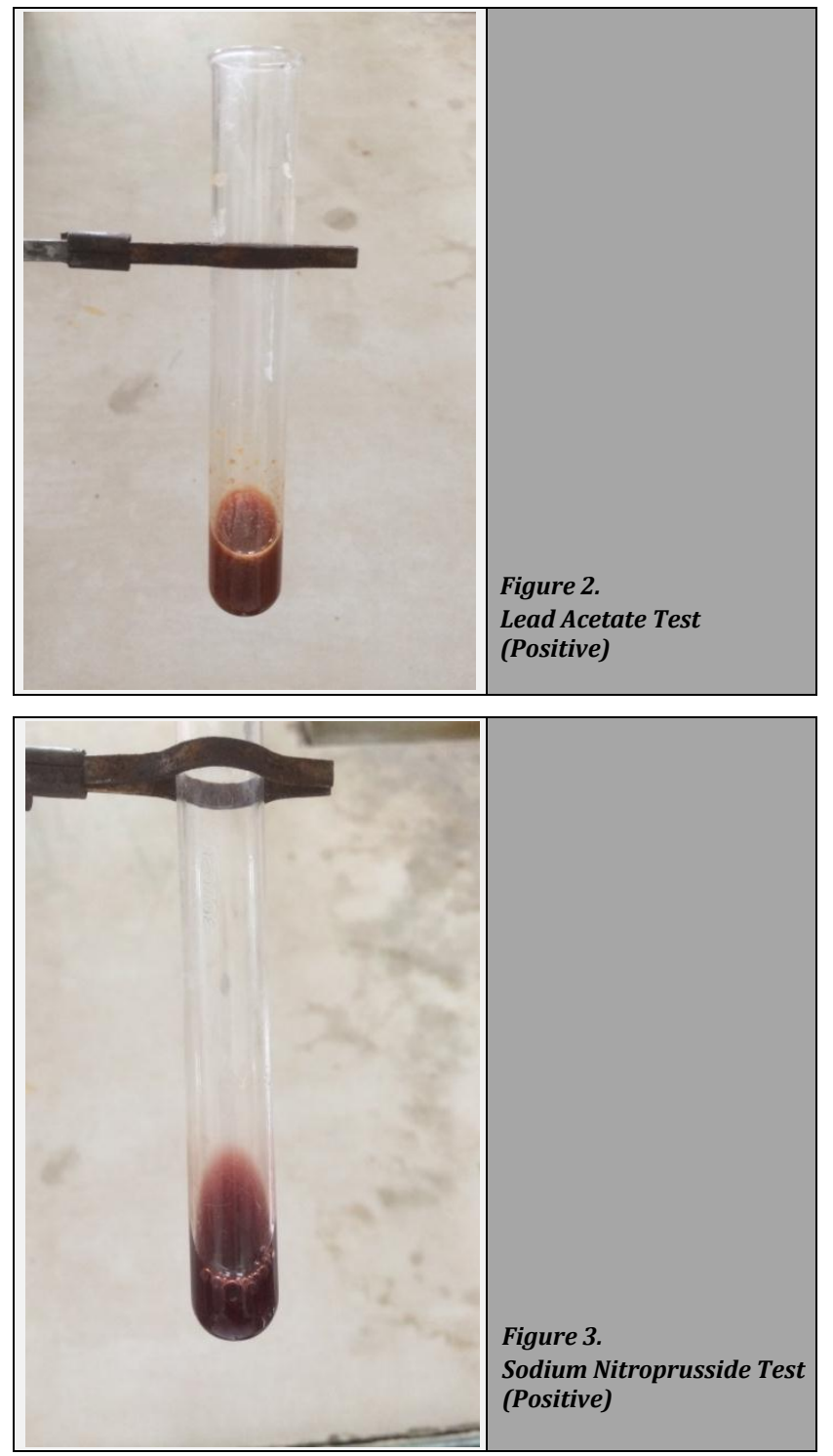

\begin{tabular}{|ccccc|}
\hline Peak\# & Ret. Time & Area & Height & Area \% \\
\hline 1 & 1.278 & 66879 & 5172 & 3.553 \\
2 & 3.011 & 1510618 & 44389 & 80.247 \\
3 & 3.647 & 62147 & 3246 & 3.301 \\
4 & 5.027 & 109819 & 7029 & 5.834 \\
5 & 8.762 & 132994 & 5104 & 7.065 \\
& Total & 1882457 & 64940 & 100.000 \\
\hline \multicolumn{5}{|c}{ Table 3. Peak Table-Sample } \\
\hline PDA Ch1 240 $\mathrm{nm}$ 4 nm
\end{tabular}

\section{DISCUSSION}

Apart from the minerals and vitamins it is the naturally occurring compounds, known as phytochemicals, that are largely responsible for the protective health benefits of plantbased foods and beverages. These phytochemicals also impart the colour, flavour, and odour of plant foods, such as blueberries' dark hue, broccoli's bitter taste, and garlic's pungent odour. Research strongly suggests that consuming foods rich in phytochemicals provides health benefits, but not enough information exists to make specific recommendations for phytochemical intake. ${ }^{7}$

Allicin is produced by an enzymatic reaction when raw garlic is crushed or chopped. However, being unstable and reactive in nature it's difficult to preserve; once it is generated, it readily changes into other compounds such as allylsulfides, vinyldithiins, and ajoenes. ${ }^{8}$

Allicin liquid forms thiosulfinate compounds. These components are difficult to measure or detect without high performance liquid chromatography. Hence, in this study we used high high performance liquid chromatography for determination of allicin in garlic.

Allicin (2-propene-1-sulfinothioic acid S-2-propenyl ester) is the most abundant thiosulfinate, typically accounting for 70 $\%(\mathrm{w} / \mathrm{w}$ ) of the total thiosulfinates (approximately $0.4 \%$ by fresh mass) found in fresh garlic. ${ }^{9}$ Studies have shown allicin to be an antimicrobial agent, ${ }^{10,11}$ and substantial evidence suggests that allicin may be the active component responsible for observed anticancer ${ }^{12}$ and antioxidant ${ }^{13}$ activity.

HPLC technique was applied for the estimation of allicin in 2012 by Rahman et al.14 reporting that except high performance liquid chromatography none other technique is reliable for the study of allicin. A study showed that the retention time of allicin seemed to vary from 3 to 3.7 minutes / $\mathrm{mL}$ in several garlic varieties, which is in accordance with our study.

Moreover, the amount of allicin present correlates with the study done by Nurlidia et al. and Mohammad Shafiur Rahman. Both of which marks the concentration of garlic between 60 $80 \%$ of thiosulphonates present in garlic. ${ }^{15,16}$

Study done by Yan Liang et al. ${ }^{17}$ and Michael E. Ryback et al. ${ }^{18}$ high performance liquid chromatography was determined as best method of allicin determination along with its presence between 70 - $80 \%$ of thiosulphonates in garlic. Lawson et al. ${ }^{19}$ and Harris et al. ${ }^{20}$ in their respective studies depicted the importance of allicin as antimicrobial, antiinflammatory, anticancer and antioxidant. Making its importance in the medical field as a potential drug.

\section{CONCLUSIONS}

With the help of two biochemical tests \& high-performance liquid chromatography, we conclude here that garlic has sulphur and allicin. Literatures suggest that allicin and sulphur are medically important chemicals present in garlic cloves.

Data sharing statement provided by the authors is available with the full text of this article at jemds.com.

Financial or other competing interests: None.

Disclosure forms provided by the authors are available with the full text of this article at jemds.com.

\section{REFERENCES}

[1] Sofowora A, Ogunbodede E, Onayade A. The role and place of medicinal plants in the strategies for disease prevention. Afr J Tradit Complement Altern Med 2013;10(5):210-29.

[2] De Sousa CA, Alviano DS, Blank AF, et al. Melissa officinalis L. essential oil: antitumoral and antioxidant activities. J Pharm Pharmacol 2004;56(5):667-81.

[3] Jelodar GA, Maleki M, Motadayen MH, et al. Effect of fenugreek, onion and garlic on blood glucose and histopathology of pancreas of alloxan-induced diabetic rats. Indian J Med Sci 2009;59(2):64-9. 
[4] Mostofa M, Choudhury ME, Hossain MA, et al. Antidiabetic effects of Catharanthusroseus, Azadirachtaindica, Allium sativum and glimepride in experimentally diabetic induced rat. Bangladesh J Vet Med 2007;5(1 \& 2):99-102.

[5] Jalal R, Bagheri SM, Moghimi A, et al. Hypoglycaemic effect of aqueous shallot and garlic extracts in with fructoseinduced insulin resistance rats. J Clin Biochem Nutr 2007;41(3):218-23.

[6] Snyder LR, Kirkland JJ, Dolan JW. Introduction to modern liquid chromatography. New York: John Wiley \& Sons 2011.

[7] Bayan L, Koulivand PH, Gorji A. Garlic: a review of potential therapeutic effects. Avicenna J Phytomed 2014;4(1):1-14.

[8] Iberl B, Winkler G, Knobloch K. Products of allicin transformations: ajoenes and dithiins, characterization and their determination by High Performance Liquid Chromatography. Planta Med 1990;56(2):202-11.

[9] Cutler RR, Wilson P. Antibacterial activity of anew, stable, aqueous extract of allicinag ainst methicillin-resistant Staphylo-coccus aureus. Br J Biomed Sci 2004;61(2):71-4

[10] Canizares P, Gracia I, Gomez LA, et al. Thermal degradation of allicin in garlic extracts and its implication on the inhibition of the in-vitro growth of Helicobacter pylori. Biotechnol Prog 2004;20(1):32-7.

[11] Park SY, Cho SJ, Kwon HC, et al. Caspase-independent cell death by allicin in human epithelial carcinoma cells: involvement of PKA. Cancer Lett 2005;224(1):123-32.

[12] Oommen S, Anto RJ, Srinivas G, et al. Allicin (from garlic) induces caspase-mediated apoptosis in cancer cells. Eur J Pharmacol 2004;485(1-3):97-103.
[13] Patya M, Zahalka MA, Vanichkin A, et al. Allicin stimulates lymphocytes and elicits an antitumor effect: a possible role of p21ras. Int Immunol 2004;16(2):275-81.

[14] Rahman MM, Fazlic V, Saad NW. Antioxidant properties of raw garlic (Allium sativam) extract. Int Food Res J 2012;19(2):589-91.

[15] Mansor N, Herng HJ, Samsudin SJ, et al. Quantification and characterization of allicin in garlic extract. Journal of Medical and Bioengineering 2016;5(1):24-7.

[16] Rahman MS. Allicin and other functional active components in garlic: health benefits and bioavailability. International Journal of Food Properties 2007;10(2):24568.

[17] Liang Y, Zhang JJ, Zhang QB, et al. Release test of alliin/alliinase double-layer tablet by High Performance Liquid Chromatography-Allicin determination. Journal of Pharmaceutical Analysis 2013;3(3):187-92.

[18] Rybak ME, Calvey EM, Harnly JM. Quantitative determination of allicin in garlic: supercritical fluid extraction and standard addition of alliin. Journal of Agricultural and Food Chemistry 2004;52(4):682-7.

[19] Lawson LD. Garlic: a review of its medicinal effects and indicated active compounds. In: Lawson LD, Bauer R, eds. Phytomedicines of Europe: chemistry and biological activity. ACS Symposium Series, American Chemical Society, Washington, DC: 1998;691:176-209.

[20] Harris JC, Cottrell SL, Plummer S, et al. Antimicrobial properties of Allium sativum (garlic). Applied Microbiology and Biotechnology 2001;57(3):282-6. 